\title{
The application of a campus production line teaching system with mixed reality technology on the skilled training of students majoring in wooden furniture making
}

\author{
Nai-Chin Wan ${ }^{1}$, I-Jui Lee ${ }^{* 2}$ \\ ${ }^{1}$ Department of Industrial Design, \\ National Taipei University of Technology, Taipei, Taiwan \\ ${ }^{2}$ Department of Industrial Design, \\ National Taipei University of Technology, Taipei, Taiwan (Corresponding author)
}

\begin{abstract}
.
With the exception of the actual class time, it is impossible for students to start the furniture production line machines in the campus woodworking factory at any time, thus, outside of class time, students are not able to independently study the production process of furniture or see the production operation status of machine processing. In addition, due to the limitations of space in the teaching area of the school, the proper configuration cannot be established according to the process of a production line, which leads to a disordered machine layout that interferes with the corresponding production of the production line. Thus, this study develops a mixed reality (MR) teaching system by combining the teaching content of the furniture production line on campus with augmented reality (AR), meaning the application of AR Foundation technology. This system enables students to master a complete virtual furniture production line in a campus woodworking factory, which allows them to understand the state of actual production when the woodworking factory is not in operation. The assessment results of the students using the teaching system indicate that the students' understanding of production line concepts have been significantly improved, as represented by their feedback in all aspects of this study.
\end{abstract}

Keywords: Augmented Reality, Teaching system for a production line on campus, mixed reality learning environments, Simulated production line, Manufacturing process of furniture

\section{Introduction}

\subsection{The study background and motive}

As the equipment for the current woodworking teaching areas are mostly small and hand-manipulated machines, equipment for the production line lack the complete implementation of furniture production capacity, thus, the actual production condition cannot correspond to the teaching content, which leads to a large gap between learning and application. In an effort to address this situation, educational institutes have started to set up furniture 


\section{$3^{\text {rd }}$ World Conference on Research in TEACHING and EDUCATION}

\section{3-25 April, 2021 Prague, Czech Republic}

production lines in campus factories for small volume production and established practice-oriented teaching environments. Depending on the degree of cooperation between production and learning, students can participate in the overall scheme of production training, including design, prototype, fabrication, and production, which allows to students to have a deeper understanding of the true industry status.

Considering the cost of providing manpower and resources after class, a campus furniture production line is not always under production, thus, students will not be able to observe the operation status of production line procedures. In particular, some machines with high difficulty and dangerous operation require the assistance of guidance personnel, meaning the students are not able to finish their assignments and practice independently. Furthermore, limited by the space available in schools, the distance between the machines, as well as the movement and workflow required by each machine, will interfere with each other; consequently, the entire production procedure cannot be presented in a complete manner. Moreover, some products have to be outsourced due to the shortage of machines or limited space. As an indirect consequence, while the production mechanism is intact, due to lack of space, the overall perception is affected, which makes it difficult for students to understand the interconnection between machines and the order and concept of their application.

The application of AR technology allows students to observe and understand the operational state of machines, even when the production line stops operating in an effective manner. In addition, by integrating virtual production procedures and physical machines, AR technology can deal with the impact of procedure operations, as caused by limited space on campus. AR technology can present the spatial information and virtual objects that are not physically available, meaning students can easily browse the virtual instructions, watch animated processing demonstrations on the virtual machine from different angles, and create realistic operational processes. Such learning style of interactive experience can assist students to understand the operation state of a furniture production line while improving their learning interest and effect.

\subsection{Purpose}

First, by introducing AR technology, this study aims to deal with the limitations that students cannot observe and operate when the furniture production line is not in operation. Moreover, with the help of AR technology, teachers can guide students to understand and master the operating state of a furniture production line on campus.

Second, this study examines space restrictions, as the production machines on campus are normally restricted by the current environment, meaning that they cannot be configured according to the production procedure, which compromises the production procedure.

Therefore, the intention of this study is to allow students to watch virtual animation demonstrations on a tablet by applying the AR technology and teaching system for a campus production line with Mixed Reality (MR), as developed by the AR Foundation technology. In this manner, the operation state and procedure of actual furniture production can be simulated. By referring to the teaching contents in class, students can obtain learning experience and comprehension that was previously difficult to achieve. Consequently, students can intensify their understanding of the production procedure of furniture production line and improve the 


\section{$3^{\text {rd }}$ World Conference on Research in TEACHING and EDUCATION}

connection between what is learned in school and the actual furniture production process in the industry.

\section{Literature review}

\subsection{The restrictions of current carpentry teaching}

With the increasing developments of the technologies and knowledge required for the production of wooden furniture, the demands of machines have been switched from single function machines to precision compound equipment with high effiency and automation. While the production procedures of factories in the industry change with new demands, the wood working facilities in schools remain old and outdated. Restricted by the current teaching environment, there are often no actual machines for students to practice. Lin and Lee (2020) mentioned that, due to incomplete production procedures, students had limited processing experience, and thus, they found it difficult to understand the abstract production procedures and concepts. Harrison (1988) pointed out that teachers should seek new teaching methods and teaching materials to deal with the differences between actual production and learning, meaning the teaching field should be as real as the actual production environment and students should be guided to improve their learning interests, in order to enhance their ability to absorb knowledge, and ultimately, promote the training of professional skills.

\subsection{The advantages of introducing Augmented Reality into the teaching of furniture production line}

Related studies have proven that augmented reality is effective at utilizing digital resources to assist teaching and learning, as creative training aids will improve students' understanding and interest, and allow teachers to express more explicit and specific information (Osman, \& Kamis, 2019); for example, Amri et al. (2020) developed a scientific training aid to instruct students in the knowledge of wood furniture manufacturing, which improved their performance in learning and their mastery of carpentry skills.

The contemporary application of AR technology to the teaching and learning of furniture woodworking makes the information enter the visualization stage, which allows students to easily understand and master course content (Mourtzis, Zogopoulos, \& Vlachou, 2018). Consequently, AR technology can make the overall learning experience more complete and understandable by placing virtual elements in the real environment and integrating the instructional information. Fernandez (2017) believed that AR technology could help students easily concretize the conceptual abstract content, and facilitate communication between teachers and students. In this manner, students' learning motive can be improved and more discussions and interactions will be triggered. (Virata, \& Castro, 2019). Therefore, a creative teaching mode with the application of digital resources significantly reduces the learning threshold of new fields and increases the learning interests and confidence of students (Lee, 2019).

Dinis et al. (2017) introduced a new type of AR teaching materials in engineering education, which improved the possible bottlenecks in learning and stimulated students' innovation and originality. In addition, the popularization of teaching applications for professional knowledge 


\section{$3^{\text {rd }}$ World Conference on Research in TEACHING and EDUCATION}

have also been enhanced in terms of the carpentry discipline (Martin, Bohuslava, \& Igor, 2018). The assistance of a teaching system for a virtual campus production line eases the burden of teachers and improves the teaching constraint of limited resources (Pan, Sun, Gao, \& Lin, 2017). Numerous virtual applications verify that AR shows excellent training effect in terms of manufacturing, assembly, and other engineering fields (Ong, \& Nee, 2013); therefore, it is a solution of high feasibility for both teachers and students to introduce AR to the procedure teaching of a furniture production line.

\section{Methodology}

\subsection{Experimental participants}

The participants of this study are 15 freshmen majoring in furniture design. While these students have basic carpentry skills, they have limited knowledge and experience in the manufacturing procedures and processes of furniture production. Furthermore, as they found it difficult to grasp the concepts of the manufacturing procedures, they were recruited for this virtual furniture production process teaching experiment.

\subsection{The development of AR teaching system for the campus production line}

The first step to establish the AR teaching system for the campus production line was to measure the space and machine positions in the woodworking factory, then the specifications of machines on the production line were gathered to draw up the layout drawing with AutoCAD. Sketch Up and 3D Max were utilized for the modelling of the 3D models of the machines and processing the appearance of the texture map. The animation of machine operation and processing procedures were drawn with 3D Max by referring to the movement state of actual machines on site. In terms of the operating interface, Illustrator was utilized to draw up and design the layout. Then, the completed model, animation, and UI graphics were imported into the Unity platform for virtual interaction integration.

AR Foundation technology was adopted for the AR spatial location, and the users can move freely in the fields, while the virtual objects are firmly fixed in the factory space coordinates, which makes the operation experience more direct and convenient. Finally, the execution file was output for installation on a Samsung Galaxy Tab A tablet to complete the development and design of the contents of the teaching system.

\subsection{Experimental design}

The teaching theme of the system designed in this study is the furniture production line in a woodworking factory on campus.

The experimental procedure is described, as follows:

\subsubsection{Fill in the pre-teaching tests}

The participating students completed a 10 question questionnaire of a furniture production line as the pre-teaching test. The degree of understanding the knowledge of a furniture production line before using the AR system was acquired from the questions regarding the differences 


\section{$3^{\text {rd }}$ World Conference on Research in TEACHING and EDUCATION}

between the furniture production line on the campus and an actual production line, including the production processes of furniture components and the advantages of automated machines

\subsubsection{Field teaching of the AR teaching system for the campus production line}

The teaching procedure of the AR teaching system for the campus production line was to divide the students into groups, 3 members per group, and the teaching time for each group was about 15 minutes. First, as the students entered the woodworking factory, they were introduced to the functions of the machines. Then, the students operated the virtual machines according to the system instructions. The procedures can be repeatedly watched after the teaching process for extra practice (Figure 1).

\section{Figure 1: The students are learning with the AR teaching system for the campus production line}

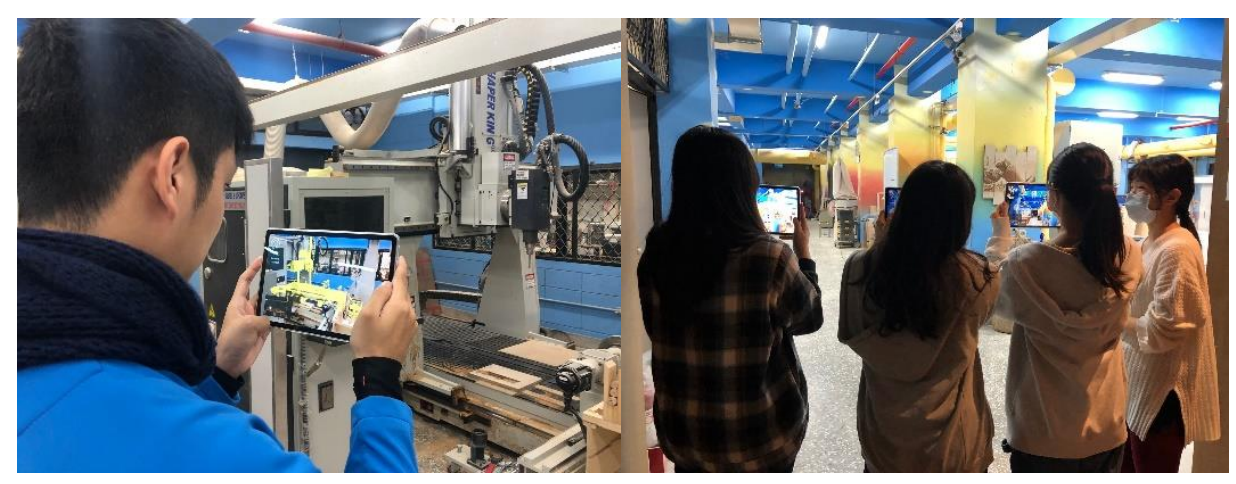

\subsubsection{Conduct the post-teaching test}

In order to understand whether this system was conducive to improving the student's understanding of the production procedure of the furniture production line, the same examination paper was used for the post-teaching test after students learned the teaching process of the AR teaching system. Then, students were asked to fill in the System Usability Scale (SUS) and were interviewed regarding their learning and operating experiences. In this manner, the usability of the system and suggestions for future improvement can be analysed.

\subsection{Experimental materials}

In order to demonstrate the difference between the furniture production line on campus and actual large-scale production lines, the mass-produced furniture of actual factories were taken as the case study for the teaching content of the system. Through such cases, the entire production procedure can be introduced, including the material preparation, shaping, polishing, assembly, coating, and packaging.

Processing animations and UI text descriptions are available for each step in the system. After the animation, the base of the scenario will display a virtual AR arrow to instruct students to the next destination. The upper area of the scenario displays the station name of the machine, as well as supporting information, in order to assist students to understand the production procedure and steps of the production line in a factory. The lower left corner of the tablet screen will display a small map with a moving spot of light to show the students where they are at this moment. 
The processing procedure is described, as follows (Figure 2): 


\section{$3^{\text {rd }}$ World Conference on Research in} TEACHING and EDUCATION

Figure 2: The presented furniture production flow chart according to the environment of the campus production line in the system

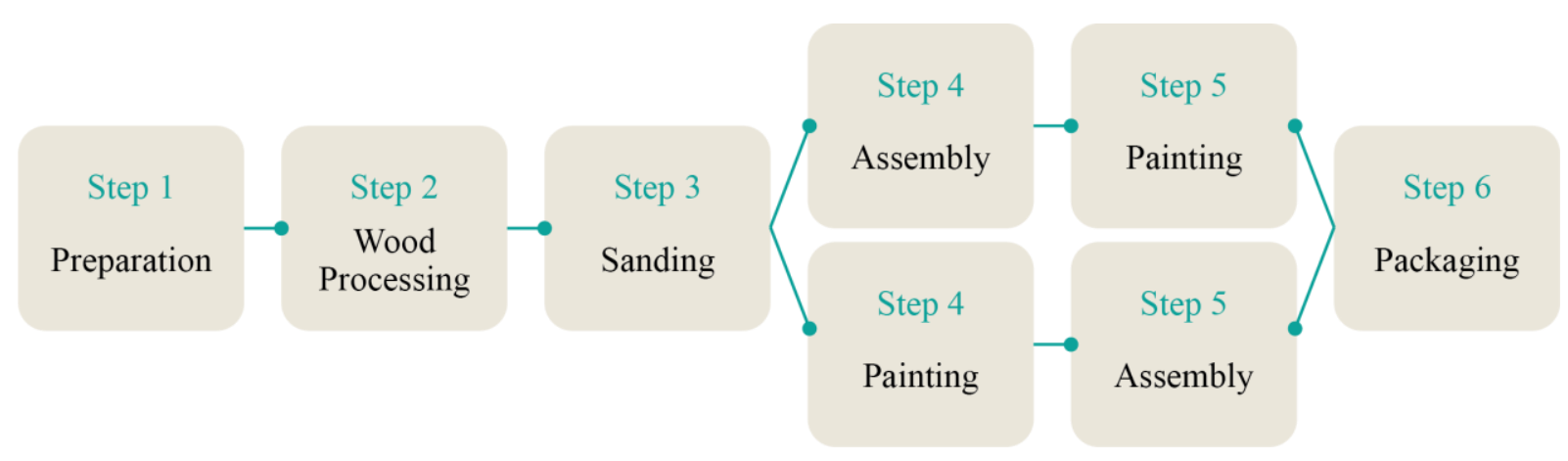

\subsubsection{Preparation}

Preparation is the first step for furniture production. The datum surface and timber size shall be preliminarily processed. Then, the Automation Guided Vehicle (AGV) in the furniture production line will automatically travel to the material preparation room to collect the processed timber from the storage area according to the pre-set route, and move the timber to the preliminary processing machine for processing (Figure $3 \& 4$ ). The students can learn the advantages of the introduction of $\mathrm{AGV}$ and the program relationship.

Figure 3: Transport the raw materials from the preparation room via $A G V$

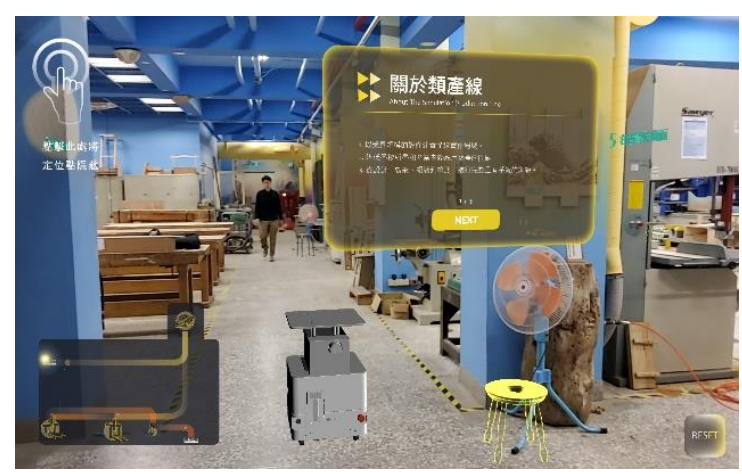

Figure 4: Animation presentation of the material preparation area

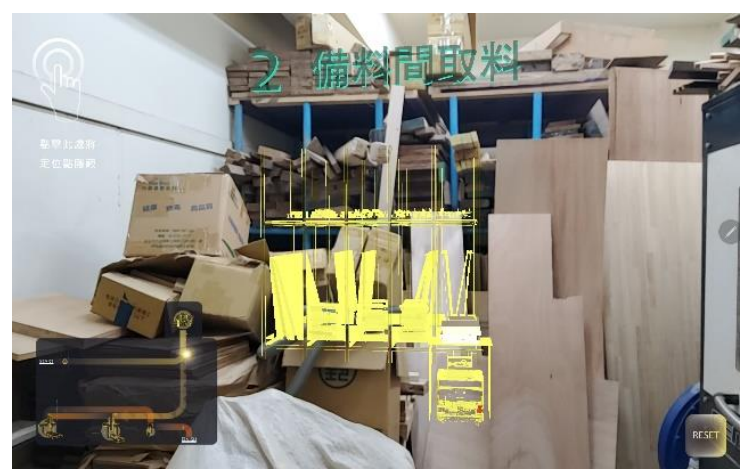




\section{$3^{\text {rd }}$ World Conference on Research in} TEACHING and EDUCATION

\section{3-25 April, 2021 Prague, Czech Republic}

\subsubsection{Wood Processing}

The second step is to process the actuate shape of the furniture through fine machining, which ensures that the shape and size conform to the requirements in the design drawing.

The students can follow the AGV animation in the system to transport the timber to the Computer Numerical Control (CNC) carving machine. The manipulator of the machine will automatically take the timber to the CNC platform. At this stage, the students can watch how the machine processes the timber into the required shape for the top and legs of the chair through animation (Figure 5).

Figure 5: The program animation to process the top of chair with CNC (Left) The program animation to process the legs of chair with CNC (Right)
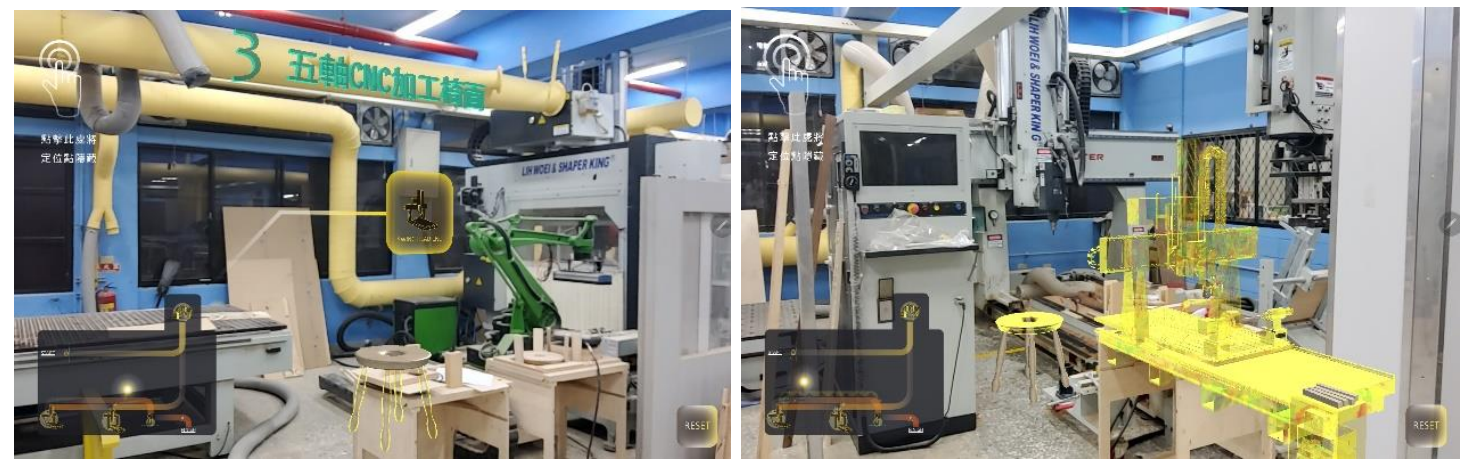

\subsubsection{Sanding}

After the basic shape and size are established, the next step is sanding the furniture to a smooth surface, which is also be the preparation for the subsequent coating. Students will follow the interface instructions of the AR teaching system and the moving animation of the AGV (Figure 6). As the AGV delivers the furniture parts to the sanding machine, the manipulator will automatically take the parts to the vibration sanding machine, thus, students can understand the advantages of using a manipulator in a production line. Automation improves efficiency and renders quality more stable.

Figure 6: Proceed to the next site for observation through the virtual arrows on the ground (Left) The virtual manipulator is clamping the chair legs for surface sanding (Right)
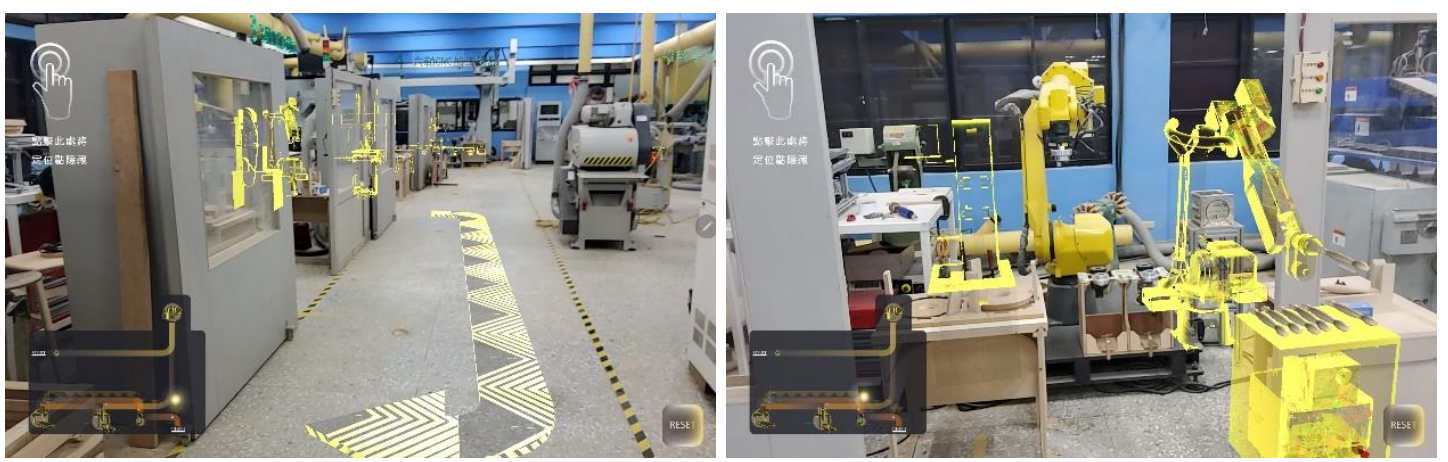


\section{$3^{\text {rd }}$ World Conference on Research in TEACHING and EDUCATION}

\subsubsection{Assembly and painting}

After sanding, according to the design of different furniture, the pieces will be assembled before coating. Assembly refers combining the parts together to make a complete piece of furniture. The painting area is where the furniture is spray painted the desired colour to protect the wooden surface. After the paint is dry, the furniture is packed, thus, completing the entire teaching process of furniture production.

\subsection{Setting}

The furniture production line site in this study is the woodworking factory of a campus, which is equipped with traditional machines and furniture production line machines, which have all been arranged according to the original space plan and production procedures. The machines are sufficient for the requirements of whole furniture production, including preparation, shape processing, sanding, painting, and assembly.

\subsection{Evaluation tools}

This study analysed the overall system, including understanding the teaching content and system usability, in order to evaluate whether the AR system is conducive to the teaching of a furniture production line and improving teaching quality.

\subsubsection{Teaching content of furniture production line and learning effect}

In terms of the differences between between the furniture production line on campus and an actual production line, the examination paper was created by comparing machines, procedures, and personnel. In addition, the examination paper included content regarding the machine applications and the processing differences of the two different production lines. In order to evaluate the learning effect of the system, the same examination paper was used before and after the application of the AR teaching system.

\subsubsection{The usability of AR system}

This study adopted the SUS questionnaire (Likert type scale), and increased the five-point scale to a seven-point scale to render data analysis more accurate. 1 7, respectively, represent: Strongly disagree (1 point), Disagree, Somewhat disagree, Neither disagree nor agree, Somewhat agree, Agree, and Strongly agree ( 7 points). The $1^{\text {st }}, 3^{\text {rd }}, 5^{\text {th }}, 7^{\text {th }}$, and $9^{\text {th }}$ questions are positive, and the $2^{\text {nd }}, 4^{\text {th }}, 6^{\text {th }}, 8^{\text {th }}$, and $10^{\text {th }}$ questions are negative. The SUS score is the total score multiplied by 2.5 . The passing score is 68 points, where the higher the score, the better the usability of the system.

\section{Research results}

\subsection{Experiment analysis}

According to the examination paper of the furniture production line and SUS questionnaire, this experiment evaluated and analysed the system according to the following four aspects: 


\subsubsection{Aspect 1: The evaluation of the learning effect of the furniture production line}

Before applying the AR teaching system, the average score of the participating students $(\mathrm{N}=15)$ was 49.3; while the average score for the same examination paper after applying the system was 72.1. In order to determine whether students' original learning effects were significantly improved after applying the AR system, the test scores were compared with the paired sample $\mathrm{t}$-Test results. The $\mathrm{t}$ appraisal results are shown in Table 1, where $\mathrm{t}$ is 0.05 and $\mathrm{p}$ is 0.001 $(\mathrm{P}<0.05)$, which indicates significant difference before and after applying the system.

Table 1: Statistic results of test scores of furniture production line

\begin{tabular}{|c|c|c|c|}
\hline & Average & t-value & p-value \\
\hline Before & 49.3 & 0.05 & 0.001 \\
\hline After & 72.1 & & 0 \\
\hline
\end{tabular}

\subsubsection{Aspect 2: The SUS evaluation}

The statistical results of the SUS questionnaire after virtual teaching are shown in Table 2 . The average SUS score for the AR teaching system is 72.7 and the average rating is B, indicating that the usability is higher than the average level. The participating students believed that the overall experience of the teaching system was good.

Table 2: The average statistic results of the SUS questionnaire

\begin{tabular}{|c|c|c|c|}
\hline Number of students & SUS Score & Grade & Adjective Rating \\
\hline 15 & 72.7 & B & Good \\
\hline
\end{tabular}

\subsubsection{Aspect 3: Content details evaluation of the teaching system}

The majority answers to the questionnaire are shown in Table 3. The participating students thought that the AR system was easy to understand and operate, that they could quickly comprehend the contents. In addition, they believed the combination of animation simulation and interactive UI could help them quickly understand the machine applications and processing procedures, and they could better understand the production procedure and operation status. As a whole, the students found that the system was conducive to rapidly learning the furniture production line procedures, improved their learning effect, and stimulated their learning interest.

Table 3: The majority answers to the SUS questionnaire

\begin{tabular}{|c|c|c|c|}
\hline Subject & Selections & Frequency & Percentage \\
\hline I think the system is easy to operate & Agree & 9 & $56.2 \%$ \\
\hline $\begin{array}{l}\text { I think I can operate the system with the assistance of someone } \\
\text { who has experience }\end{array}$ & $\begin{array}{l}\text { Somewhat } \\
\text { Disagree }\end{array}$ & 5 & $31.2 \%$ \\
\hline $\begin{array}{l}\text { I think the teaching contents of the system are perfectly } \\
\text { understandable }\end{array}$ & $\begin{array}{l}\text { Strongly } \\
\text { Agree }\end{array}$ & 5 & $31.2 \%$ \\
\hline I think the system is too complicated & Nature & 5 & $31.2 \%$ \\
\hline $\begin{array}{l}\text { I think the system can help me understand the teaching content } \\
\text { easily }\end{array}$ & $\begin{array}{l}\text { Somewhat } \\
\text { Agree }\end{array}$ & 8 & $50.0 \%$ \\
\hline I think there are many inconsistencies in the system & Disagree & 5 & $31.2 \%$ \\
\hline $\begin{array}{l}\text { I think the system makes the machine application and processing } \\
\text { mode more understandable }\end{array}$ & $\begin{array}{l}\text { Strongly } \\
\text { Agree }\end{array}$ & 5 & $31.2 \%$ \\
\hline $\begin{array}{l}\text { I think the system fails to assist students to understand the } \\
\text { production line }\end{array}$ & $\begin{array}{l}\text { Strongly } \\
\text { Disagree }\end{array}$ & 5 & $31.2 \%$ \\
\hline
\end{tabular}




\begin{tabular}{|l|c|c|c|}
\hline $\begin{array}{l}\text { I think the system makes the production procedure of the } \\
\text { production line more understandable }\end{array}$ & Agree & 6 & $37.5 \%$ \\
\hline I think the system fails to improve my learning interest & $\begin{array}{c}\text { Somewhat } \\
\text { Disagree }\end{array}$ & 7 & $43.7 \%$ \\
\hline
\end{tabular}

\subsubsection{Aspect 4: Experience feedback from users of the teaching system}

The participating students were interviewed after the experiment and examination test in order to learn about their experience with the AR system, and the positive and negative feedback were received according to the following four points.

- The machine function and operating procedure of the production line can be understood more easily:

The students said the combination of animation and literal explanation in the actual environment made understanding easier. As they could clearly see the machine processing and procedure through the AR system, it was clearer than watching the demonstration conducted during the actual operation class.

- It makes learning more vivid and interesting:

The operation method of the AR system is clear and easy to understand, and is presented in a more novel and amusing mode than the general teaching mode. Moreover, the students felt that the background music of the system helped them to feel pleasant and relaxed, which improved their learning interest.

- Students can review by themselves after class:

The students thought that they would gradually forget what they learned in class after a while. However, as this system allows students to review and practice after class, it sets the information more firmly in their minds.

- Problems encountered:

During operation, as the positioning origin of the AR machines may deviate, it leads to deviation of the UI and machine, thus, some students felt dizzy when they walked and watched the AR demonstration on the tablet. However, such problems are the inherent limitations of the device itself, and not the application of the system.

\section{Conclusions}

As known from the above analysis, by combining animation and interface assistance for the actual environment, augmented reality can help students understand machine functions and production line operations more easily. As students can operate a tablet to learn and understand the entire production procedure without the limitation of the actual field, the visualized information interface and interactive properties of this system make the learning process more vivid and interesting, which creates better learning experience and effect.

The system proposed in this study adopted AR Foundation spatial positioning technology to make the operation simpler and more direct. The participating students were able to watch the virtual animation and UI text display while walking in the actual factory. Thus, the entire 


\section{$3^{\text {rd }}$ World Conference on Research in TEACHING and EDUCATION}

teaching process continuously maintained connectivity, which is suitable for presentation requiring holistic understanding.

The results of this study indicate that the application of the AR teaching mode can better make up for the limitations of an actual environment and present more contextual information. In this manner, knowledge deviations regarding specific operations are significantly reduced, which render the machine functions and production line operations more understandable. The visualization and interactive operation make learning more vivid and interesting, and students can review and practice by themselves after class.

\section{Future development}

The application of AR on the teaching of a furniture production line has obtained significant teaching effect and a better degree of learning satisfaction. Further developments and research can be conducted by referring to the contents of the AR system in this study to expand its application to the relative teaching demands of various production lines.

\section{Acknowledgments.}

We are grateful to the MOE Teaching Practice Research Program for providing the development funds for the construction and design of the AR training system.

\section{References}

Amri, A. N., Azman, M. A., Shah, A., \& Kassymova, G. K. (2020). Integrated Special Education Program Students Involvement of the Woodworking Training Skills by Using Teaching Aid. Opción, 36, 1964-1986.

Dinis, F. M., Guimarães, A. S., Carvalho, B. R., \& Martins, J. P. P. (2017, April). Virtual and augmented reality game-based applications to civil engineering education. In 2017 IEEE Global Engineering Education Conference (EDUCON) (pp. 1683-1688). IEEE.

Fernandez, M. (2017). Augmented virtual reality: How to improve education systems. Higher Learning Research Communications, 7(1), 1-15.

Harrison, C. (1988). A Study to Determine the Effectiveness of a Traditional Teacher Directed Lecture-Demonstration Method Compared with a Computer Driven Tutorial Program for Students Enrolled in Woodworking Technology.

Lee, I. J. (2019). Using augmented reality to train students to visualize three-dimensional drawings of mortise-tenon joints in furniture carpentry. Interactive Learning Environments, $1-15$.

Lin, Y. T., \& Lee, I. J. (2020, July). Development of an augmented reality system achieving in cnc machine operation simulations in furniture trial teaching course. In International Conference on Human-Computer Interaction (pp. 121-135). Springer, Cham. 


\section{$3^{\text {rd }}$ World Conference on Research in TEACHING and EDUCATION}

Martin, J., Bohuslava, J., \& Igor, H. (2018, September). Augmented reality in education 4.0. In 2018 IEEE 13th International Scientific and Technical Conference on Computer Sciences and Information Technologies (CSIT) (Vol. 1, pp. 231-236). IEEE.

Mourtzis, D., Zogopoulos, V., \& Vlachou, E. (2018). Augmented reality supported product design towards industry 4.0: a teaching factory paradigm. Procedia manufacturing, 23, 207-212.

Ong, S. K., \& Nee, A. Y. C. (2013). Virtual and augmented reality applications in manufacturing. Springer Science \& Business Media.

Osman, N. W., \& Kamis, A. (2019). Innovation leadership for sustainable organizational climate in institution of technical and vocational education and training (TVET) in Malaysia. Asian Journal of Assessment in Teaching and Learning, 9(1), 57-64.

Pan, X., Sun, X., Wang, H., Gao, S., Wang, N., \& Lin, Z. (2017, November). Application of an assistant teaching system based on mobile augmented reality (AR) for course design of mechanical manufacturing process. In 2017 IEEE 9th International Conference on Engineering Education (ICEED) (pp. 192-196). IEEE.

Trifiletti, J. J., Frith, G. H., \& Armstrong, S. (1984). Microcomputers versus resource rooms for LD students: A preliminary investigation of the effects on math skills. Learning Disability Quarterly, 7(1), 69-76.

Virata, R. O., \& Castro, J. D. L. (2019, January). Augmented reality in science classroom: Perceived effects in education, visualization and information processing. In Proceedings of the 10th International Conference on E-Education, E-Business, E-Management and E-Learning (pp. 85-92). 